\title{
Load shifting impact on generating adequacy assessment during peak period
}

\author{
Malik Abdulrazzaq Jabbar Alsaedi ${ }^{1}$, Hussein Jumma Jabir ${ }^{1}$, Baraa Munqith Albaker ${ }^{2}$ \\ ${ }^{1}$ Department of Electrical Engineering, College of Engineering, Aliraqia University, Baghdad, Iraq \\ ${ }^{2}$ Department of Networks Engineering, College of Engineering, Aliraqia University, Baghdad, Iraq
}

\begin{tabular}{l} 
Article Info \\
Article history: \\
Received Nov 9, 2021 \\
Revised Dec 13, 2021 \\
Accepted Jan 11, 2022 \\
\hline Keywords: \\
Adequacy of supply \\
Demand-side management \\
Generating system adequacy \\
Peaking unit \\
Preventive and corrective load \\
shifting
\end{tabular}

\begin{abstract}
The load shifting technique is widely implemented in electrical power generation due to its considerable impact on system reliability. The evaluation of load shifting benefits towards the adequacy of generation systems requires an accurate assessment. If the generation unit's capacity is insufficient to meet the system load, then assistance is required from alternative sources. Load shifting, as a primary demand-side management technique, is used efficiently in electrical power networks given that the energy clipped/curtailed owing to load curtailment and peak clipping can be recovered during the off-peak period. The reliability of a generic framework for the prospective integration of a load shifting technique, with preventative and corrective actions as alternatives to peaking units, is investigated in this study. The optimal rate of load shifting in terms of expected energy not supplied is also investigated. Results show that preventive load shifting (PLS) can act as peaking units when the total generated capacity is within specific limits. Meanwhile, corrective load shifting can act as a better alternative than PLS and peaking units. To calculate expected energy not supplied, sequential Monte Carlo simulation is utilized. This study is conducted using the IEEE reliability test system.
\end{abstract}

This is an open access article under the CC BY-SA license.

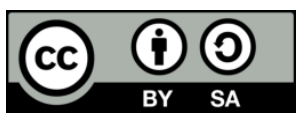

\section{Corresponding Author:}

Hussein Jumma Jabir

Department of Electrical Engineering, College of Engineering, Aliraqia University

Sab'abkar, 10054, Baghdad, Iraq

Email: hjjahmn@gmail.com

\section{INTRODUCTION}

The electric utility industry has to supply reliable electricity to consumers at the lowest feasible cost. It is, nevertheless, impracticable to design and build completely reliable electrical power networks. As a result, power system planners try to design a system with a reasonable level of reliability while keeping the initial and operating costs low. The adequacy study of generating systems focuses on the ability of generation systems to satisfy customer demands without considering transmission line and distribution system facilities [1]. Demand-side management (DSM) programmes refer to any action that aims to change demand shape [2]. Demand response is effective tool to reducing the number of peaks [3]. The reliability of power systems can be enhanced as peak loads are reduced [4], [5]. Consequently, reserve margin can be used more optimally without constructing new generation units [6].

Many utilities services regard load shifting as promising alternatives to peaking generation units. Thus, an accurate assessment of load shifting's influence on generation system adequacy is essential, bearing in mind that the primary purpose of load shifting is risk mitigation. Load shifting techniques are typically implemented either to mitigate system risk or to correct load curtailed due to unplanned outages. Corrective 
load shifting (CLS) is applied instantaneously after the occurrence of adequacy deficiency, whereas preventive load shifting (PLS) is applied prior to a high-risk period [7], [8].

Considerable work has been performed on the load shifting technique as peaking units. Load shifting has been proposed under generation adequacy assessment to measure the influance of peak shaving activity on the production cost and reliability [9]. Peak clipping activity has been thoroughly studied in [10] to assess its effect on the reserve margin and available generating capacity. The adequacy resources have been coordinated to boost peak load control capability in presence of wind power [11]. The impact of renewable energies penetration and peak reduction has been addressed in [12]-[14] to assess the capacity adequacy of an energy system. Load shifting has been investigated to determine the adequacy of the reserve margin for Indiana's electricity generation system [15]. The impact of peak load uncertainties on the generation expansion planning is investigated [16]. The impact of changing system peak on the reliabilty indices was investigated [17]. The appropriateness of generating systems related with intermittent functioning units, necessary reserve, and system peak load had been investigated [18]. Battery energy storage systems and demand response have been proposed based on peak matching applications [19]. The shiftable loads priority technique was addressed based on the load demand to reduce the peak demand, utility risk and production cost [20]. The adequacy of supply assessment and peak load satisfaction were investigated [21]. The generation adequacy assessment was evaluetd based on peak periods [22].

However, little research has been conducted to analyse the influence of DSM on the generating adequacy assessment. As well, no literature has provided a quantitative basis of PLS and CLS measures as alternatives to peaking units. The current study intends to fill in such gap. Because load shifting is a widely used DSM technique in electrical power networks, this study exclusively looks at this activity. The basic load shifting goals in the design phase of generating system adequacy are quantified using PLS and CLS.

The rest of this paper is structured as shown in: Methodologies of PLS and CLS as alternatives to peaking units are described in section 2. Section 3 contains the findings and discussions. The conclusion of the study is provided in section 4 .

\section{METHOD}

Generation, transmission, and distribution are the three hierarchical levels (HLs) in which electric power systems are classified. HL1 includes only the generation systems; HL2 considers the generation systems and transmission lines; HL3 involves additional distribution systems. HL1 assessment is also called the generating system adequacy study. The ability of generating systems to meet consumer demand is the sole focus of assessing their adequacy. This study focuses on HL1 assessment. Peak clipping/load curtailment and valley filling procedures are used in the load shifting technique. It operates by reducing load during the on-peak period or restricting load owing to adequacy efficiency and replenishing it during the off-peak period.

By merging the generation and load models, the system risk model is created. The expected energy not supplied (EENS) value is then calculated. EENS is evaluated using sequential Monte Carlo simulation (MCS) in this work. Sequential MCS models the real process of generation systems as well as their unpredictable behavior. EENS is calculated by multiplying hourly load data by the total available capacity of generating units and calculating power deficiency in terms of energy. The proposed methodology is divided into four steps as shown in:

Step 1: EENS is calculated with the original load model.

Step 2: The impact of load shifting rate is investigated to achieve an optimal EENS.

Step 3: The impact of PLS and CLS on EENS are assessed.

Step 4: The impacts of PLS and CLS as alternatives to peaking units are assessed and compared.

In this step, peaking units are removed from the generating adequacy assessment to investigate the impacts of PLS and CLS as alternatives to these units in terms of reliability. A two-state model is typically used to assess generating capacity adequacy, in which all generators transit only between down and up states without considering the types of generation unit and their partial outage [1]. Sequential MCS is performed in accordance with a chronological load model to calculate EENS. For system modeling and simulation, MATLAB software is employed. Sequential MCS has a sample size of 3000 iterations. The generation systems and hourly load profile of the IEEE reliability test system (RTS) are implemented [23], [24]. IEEE-RTS's generating system model includes 8736 load data points and a generating capacity of 3405 MW installed. Figure 1 depicts the IEEE-RTS schematic.

In one day, on-peak hours comprise the period of 1-16 hours, whereas the off-peak hours are between 17 and 24. The likelihood of a peaking unit failing to start-up is considered to be 0.03 [1]. Because the loading order of the generators has a significant influence on system production costs, this study uses a priority list technique. The priority order, capacity, and type of each generation unit, as well as the estimated 
energy delivered by each type of generation unit, are listed in Table 1 . The estimated energy delivered by each generator falls as the priority order rises [23], [25]. According to the chronological load level, load is split into three types: base, cycling, and peaking loads. As a result, generating units are classified according to the sort of load they supply. Base, cyclic, and peaking generating units are the three categories.

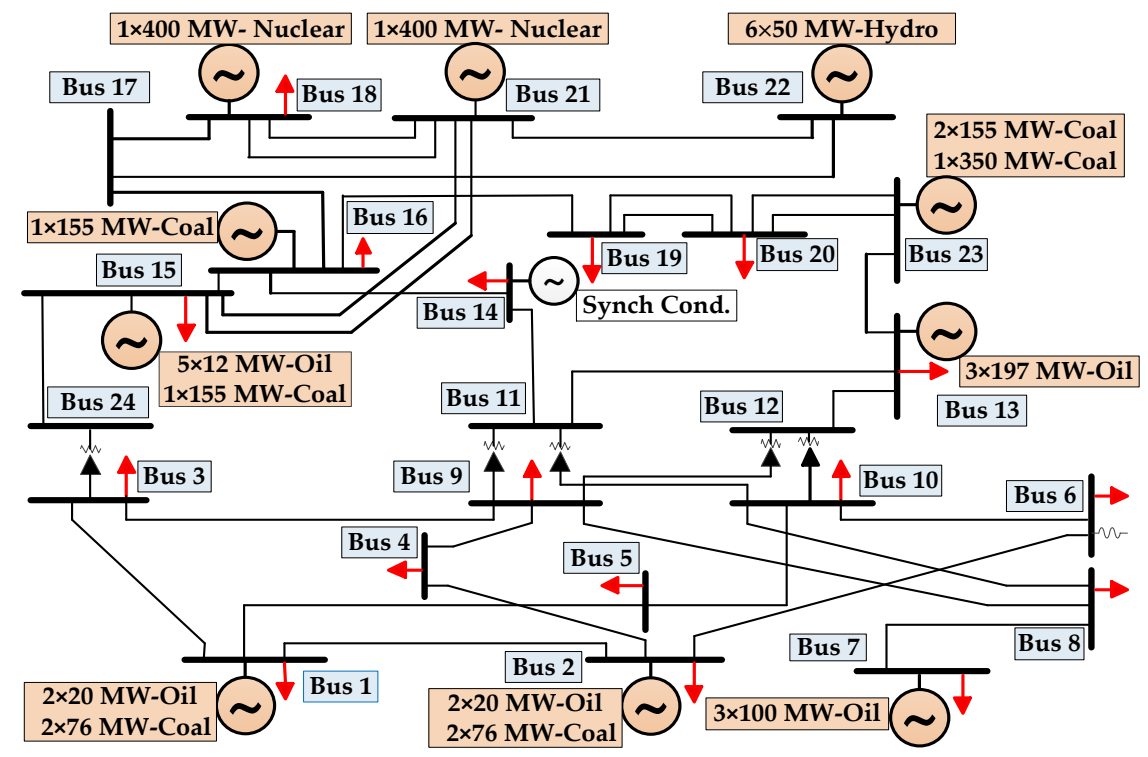

Figure 1. Schematic of IEEE-RTS

Table 1. Priority order of the base, peaking and cycling generation units

\begin{tabular}{ccccc}
\hline Priority order & Capacity (MW) & Unit type & Expected energy supplied (GWh) & Load supplied \\
\hline $1-6$ & $50 \times 6$ & Hydro & 2594.592 & \\
$7-8$ & $400 \times 2$ & Nuclear & 6142.754 & Base \\
9 & $350 \times 1$ & Coal & 2521.737 & \\
$10-12$ & $197 \times 3$ & Oil & 3002.401 & \\
$13-16$ & $155 \times 4$ & Coal & 680.454 & Cycling \\
$17-19$ & $100 \times 3$ & Oil & 333.287 & \\
$20-23$ & $76 \times 4$ & Coal & 18.638 & Peaking \\
$24-28$ & $12 \times 5$ & Oil & 1.149 & \\
$29-32$ & $20 \times 4$ & Oil & 0.885 & \\
\hline
\end{tabular}

\subsection{Model for capacity adequacy generation}

Using the PLS and CLS procedures, this section briefly explains many well-known methodologies for generating capacity adequacy evaluation in power system adequacy studies. The process of determining whole generating system sufficiency to satisfy system demand criteria is known as HL1 reliability evaluation. The primary goal of such an evaluation is to determine the amount of system reserve necessary to meet system demand. This assessment is split into two parts: static and operational adequacy assessments. Static assessment is a prerequisite for long-term planning to fulfill the load. The short-term capacity required to fulfill demand is the subject of operating capacity evaluation [1]. The generation and load models are used to estimate the adequacy of generating capacity. A risk model is created by combining the two models.

\subsubsection{Load model}

Load may be modelled in a variety of ways to reflect demand over a period of time. For a corresponding period, the simplest model is fixed load. Because it depicts the static status of a load, this model is rarely employed. Hourly load data may be modeled in a chronological order as well. The available hourly data is used to create a chronological load model. The 24-hour load profile, daily and weekly percentages, and the yearly peak load are used to create the annual hourly load model that is implemented in this study. 


\subsubsection{Available capacity of generation units using MCS}

By simulating the unpredictable behavior of the generator unit's failure, sequential MCS is utilized to estimate EENS. After that, a risk model is created by overlaying the chronological load model on the entire available capacity of the system. Mean times to failure (MTTF) and mean times to repair (MTTR) are used to track the operating history of each single generation unit. As demonstrated in (1) and (2), these parameters represent the reciprocal of the repair rates and failure rates, respectively.

$$
\begin{aligned}
& \text { MTTR }=1 / \mu \\
& \text { MTTF }=1 / \lambda
\end{aligned}
$$

Random values in the range of 0 to 1 are utilized with MTTR and MTTF to create a state history for each generator. In this study, exponential probability distributions are assumed. Each generator's state history is made up of a series of random up-down-up or up-derated-down-up times. Time-to-repair (TTR) and time-to-failure (TTF) are calculated using (3) and (4).

$$
\begin{aligned}
& \text { TTF }=- \text { MTTFInU } \\
& \text { TTR }=- \text { MTTRInU }
\end{aligned}
$$

where $U$ is a random number, $\lambda$ the failure rate, and $\mu$ the repair rate.

\subsubsection{Risk model}

The risk model or the system's possible margin model is created by superimposing the generation and load models. A positive value of the available margin shows that the energy provided is sufficient to meet system demand, but a negative number indicates that system generation is insufficient. Hence, some of the system demand must be shed. The average amount of load loss due to generator insufficiency is depicted by EENS. In each sampled year, e.g. in year $i$, the energy not provided $\left(E N S_{i}\right)$ in MWh is calculated using the available capacity. EENS in $s$ sampling years is calculated using [1].

$$
E E N S=\frac{\sum_{i=1}^{S} E N S_{i}}{s} M W h / \text { year }
$$

\subsection{Preventive and corrective load shifting model}

PLS and CLS models are discussed comprehensively in [7], [8]. Load shifting is a mixture of peak clipping and valley filling procedures. In this study, the whole cycle of this strategy is considered 24 hours. A restricted load is declared lost if it cannot be filled within the specified time frame ( 24 hours). As shown in (6) and (7) provide the mathematical model of peak clipping, whereas (8) and (9) represent the mathematical model of valley filling measure.

$$
\begin{aligned}
& \bar{D}_{t}=D_{t}-\left(\left(D_{t}-p\right) X_{t}\right) \\
& \text { where } X_{t}=\left\{\begin{array}{c}
1 \text { if } D_{t}>p \\
0 \text { otherwise }
\end{array}\right. \\
& \overline{\bar{D}}_{t}=\bar{D}_{t}+\left(A \frac{\left.\sum_{a}^{b_{\{}} D_{t}-\left(D_{t}-p\right) X_{t}\right\}}{n} R_{t}\right) \\
& R_{t}=\left\{\begin{array}{c}
1 \text { for } t_{7} \leq t \leq t_{8} \\
0 \text { otherwise }
\end{array}\right.
\end{aligned}
$$

Where $D_{t}$ is the system's initial demand; $\bar{D}_{t}$ and $\overline{\bar{D}}_{t}$ are the changed system load curves that arise from executing a load-shifting operation; $p$ is the pre-determined peak load level that cannot be exceeded; the percentage of energy recovered during off-peak hours is called A, and it ranges from 0 to 1; and the first and last hours, respectively, are a and $\mathrm{b}$. When the initial load is more than $p\left(D_{t}>p\right) ; t_{7}$ and $t_{8}$, respectively, are the beginning and last hours for energy recovery during off-peak hours; and $n$ is the length supplied by the difference between $t_{7}$ and $t_{8}$. The CLS method is represented as shown in (10):

$$
\dot{\mathrm{D}}_{t}=D_{t}-E N S_{t}
$$


Where $\dot{\mathrm{D}}_{t}$ is the initial adjected load curve upon subtracting the instantaneous energy not supplied $\left(E N S_{t}\right)$ from the original load. $E N S_{t}$ is the amount of energy that must be expended during a period of insufficient power supply. The recovery of curtailed energy is only taken into account on the same day that the load was reduced. The amount of the system load that is equal to or more than the average curtailed energy per interruption is considered to be under direct control of the system operators in this research, and they are permitted to transfer the load wholly or partially during this period of time. The recovery of energy curtailment due to generator failures is not assured, however. The CLS load shifting model is represented as:

$$
\begin{aligned}
& \ddot{D}_{\mathrm{t}}=\dot{\mathrm{D}}_{\mathrm{t}}+\mathrm{M}-\mathrm{ENR}_{\mathrm{t}} \\
& M=\left(R\left(\frac{\Sigma_{\mathfrak{t}_{1}}^{\dot{t}_{2}}\{\text { ENS }\}}{n}\right) C_{\left(\mathfrak{t}_{3}, \dot{t}_{4}\right)}\right) \\
& \mathrm{C}_{(\mathfrak{\mathrm { t }} 3, \dot{\mathrm{t}} 4)}=\left\{\begin{array}{c}
1 \text { for } \dot{\mathrm{t}}_{3} \leq \mathrm{t} \leq \dot{\mathrm{t}}_{4} \\
0 \text { otherwise }
\end{array}\right. \\
& \mathrm{ENR}_{\mathrm{t}}=\dot{\mathrm{D}}_{\mathrm{t}}+\mathrm{M}-\mathrm{SAC}_{\mathrm{t}} \mathrm{Z}_{\mathrm{t}} \\
& \mathrm{Z}_{\mathrm{t}}=\left\{\begin{array}{c}
1 \text { for } \mathrm{SAC}_{\mathrm{t}}<\dot{\mathrm{D}}_{\mathrm{t}}+\mathrm{M} \\
0 \text { otherwise }
\end{array}\right. \\
& \mathrm{EENR}=\sum_{\mathrm{i \epsilon S}} \mathrm{ENR}_{\mathrm{t}} / \mathrm{X}(\mathrm{MWh} / \text { year })
\end{aligned}
$$

Where $\ddot{D}_{t}$ is the second adjusted load curve after recovering the reduced load from (10); $M$ is the amount of additional energy to each hour of recovery time; $E N R_{t}$ is the energy not recovered during each hour of energy recovery time; $R$ denotes the proportion of energy recovered, with a range of 0 to 1 ; the earliest time throughout the day when the original load exceeds system available capacity is $\dot{t}_{1}$; the last time during the day when the original load equals or falls below system available capacity is $\dot{t}_{2}$; The starting and finishing times for off-peak energy recovery are $\dot{t}_{3}$ and $\dot{t}_{4}$, respectively; the difference between $\dot{t}_{3}$ and $\dot{t}_{4}$; is $\mathrm{n}$; the instantaneous system available capacity is $S A C_{t}$; and The anticipated energy not recovered is denoted by $E E N R$, while the number of years is denoted by $X$.

\section{RESULTS AND DISCUSSIONS}

This section is divided into three parts. Part 1 involves the impact of PLS on EENS. Part 2 addresses the comparison of the impacts of PLS and CLS on EENS. Part 3 addresses the impacts of PLS and CLS as alternatives to peaking units. EENS is solely used to determine if there is adequacy insufficiency in all parts.

\subsection{Effects of PLS on EENS}

PLS is a useful and effective activity because it moves demand from on-peak to off-peak hours rather than restricting provided energy. During valley hours, the cut energy at peak hours is recovered. Peak cutting assumes $0 \%-20 \%$ of peak load, with $1 \%$ increments, whereas energy recovery assumes $100 \%$ of the cut energy. The energy not recovered (ENR) and the insufficiency of the generating systems owing to random generator failures both contribute to the EENS value [7], [8]. After that, both are added together to get the total EENS. Energy recovery following peak clipping action is required for load shifting. However, if peak clipping is increased to a certain level, load shifting may exacerbate EENS. The effect of load shifting rate on EENS is seen in Figure 2.

Figure 2 indicates that EENS improves up to $15 \%$ of the peak clipping. At $16 \%$ onwards, EENS begins to deteriorate, whereas above $18 \%$, EENS becomes greater than the EENS baseline value, which is equal to $446.5633 \mathrm{MWh} /$ year. The inability to restore the complete cut energy during the off-peak time is the cause of this degeneration. This study suggests that the load shifting action's peak clipping must be set at an optimal level. As a result, if an effective and acceptable rate of peak clipping is used, the load shifting action provides a practical opportunity. Because load shifting is more widely used than other DSM activities, this study focuses on it. As a result, a thorough analysis and examination are necessary to demonstrate the impact of load shifting on EENS. 


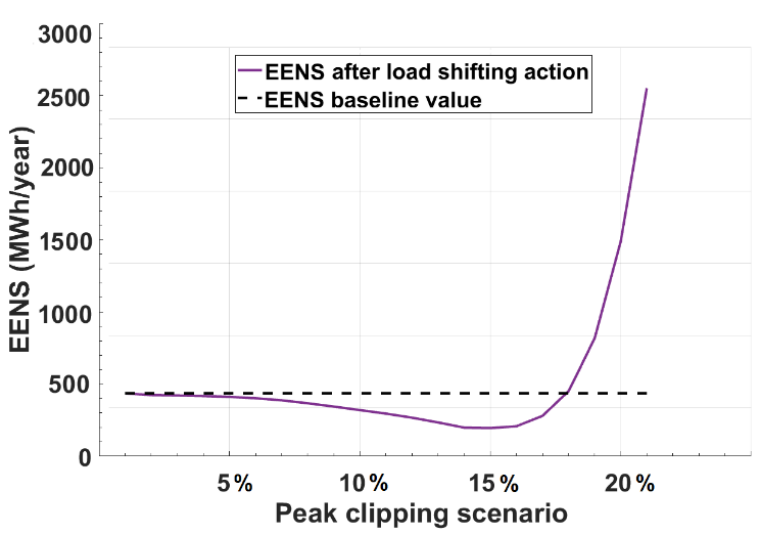

Figure 2. Impact of load shifting action on EENS

\subsection{Effects of PLS and CLS on EENS}

The findings are grouped into two case studies in this section. Case 1 is the most common scenario, in which EENS is obtained by utilizing the original load. The other cases are similar to Case 1, except that PLS and CLS are implemented separately in each case. PLS and CLS energy recovery is considered to be $100 \%$ of the clipped/curtailed energy. Based on the results of Figure 2, peak clipping is considered to be $15 \%$ of the peak load. The reasons for this rate selection are as shown in. i) No ENR exists at this rate and ii) This rate has an optimal EENS value. Table 2 presents the results of EENS with the two case studies.

Table 2. Impacts of PLS and CLS on EENS
\begin{tabular}{ccc}
\multicolumn{3}{c}{ EENS (MWh/yr) } \\
Base value & PLS & CLS \\
\hline 1197.4448 & 724.0161 & 68.9158 \\
\hline
\end{tabular}

The EENS value of the two-state model is 1197.4448 MWh/year [7], [8]. The following is a discussion of the impact of PLS and CLS on EENS. The EENS value is greater than PLS and CLS when load shifting is not employed. This emphasizes the load-shifting measures' reliability benefits. When PLS is taken into account, EENS improves by approximately twice as much. When CLS is taken into account, the EENS value drops dramatically, enhancing the index values by $90 \%$. This in turn implies that CLS has a substantial influence on generation systems' reliability. The CLS program is utilized when the power supply is inadequate to fulfill the load demand, offering a more particular approach to the load curve modification. This finding demonstrates that CLS has a significant influence on EENS.

\subsection{Effects of PLS and CLS as alternatives to peaking units}

Because of interruptions, planned maintenance, and reserve margin operation requirements, the total energy capacity for each generation unit in IEEE-RTS cannot be delivered completely throughout the year. As a result, the residual energy is the energy that is expected to be given. To keep the system safe through outages and abrupt increases in demand, the utility must generate more energy than demands. Peak load units are needed for just a few hours per year, but base load units are needed for practically all hours across the year, as seen in Figure 3. The load duration curve (LDC) and capability for each type of IEEE-RTS generating unit are shown in this figure in priority order, without taking into account the effect of generating system failure. The amount of demand in LDC is increasing in size. The energy required by the system is represented by the area beneath the LDC. Total power demand levels must be higher than LDC to meet load demand. Figure 3 depicts the link between each producing unit's capacity and the load's capacity usage. Peaking load units are rarely used to provide energy and are only needed for a short period of time during the year. These load units are more expensive to produce than base load units and are typically employed during peak demand. Furthermore, peaking load units are frequently required not just during peak periods, but also when total available capacity is insufficient to meet demand. The goal of the load shifting programme is to avoid using peaking load units. The load shifting programme, in other words, can operate as peaking load units.

Indonesian J Elec Eng \& Comp Sci, Vol. 25, No. 3, March 2022: 1217-1226 


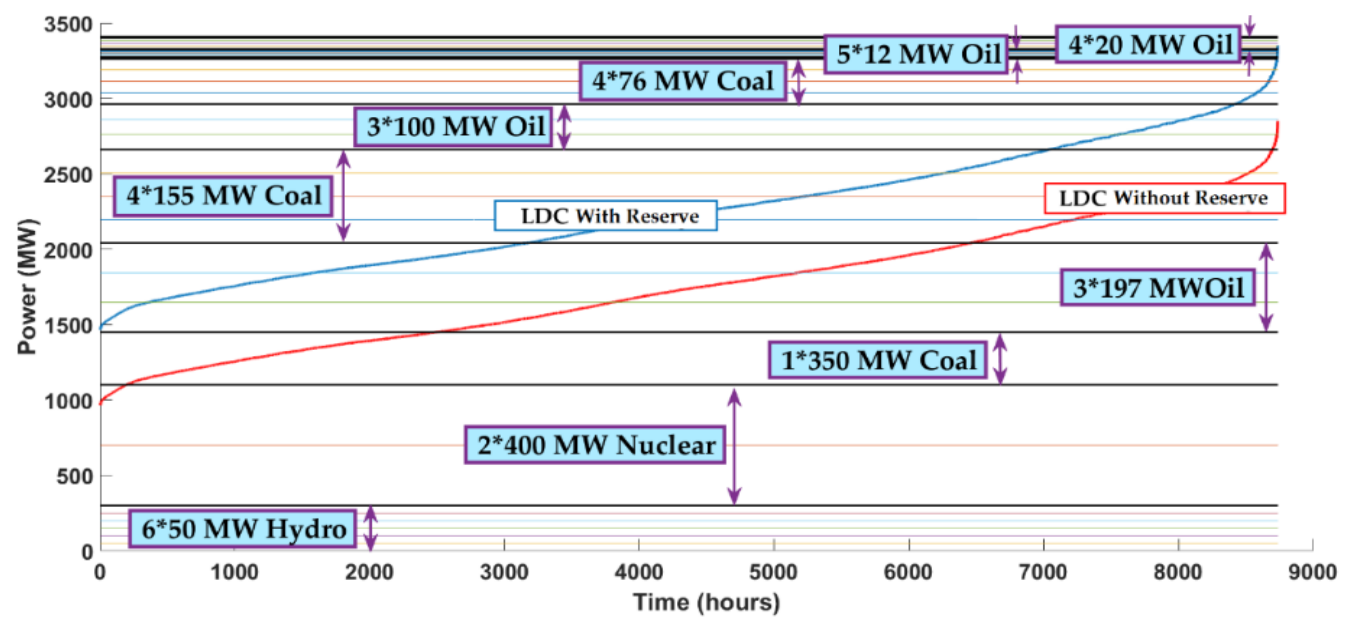

Figure 3. LDC and constraints for each type of generating unit

Table 3 presents the results of EENS with the two case studies from Section 3.2 when all the peaking units are removed from the assessment. In this table, PLS and CLS energy recovery is considered to be $100 \%$ of the clipped/curtailed energy. For PLS, $15 \%$ of the peak load is considered to be clipped. This rate is selected because it has an optimal EENS value. Table 4 shows the EENS of PLS and CLS when the nine peaking units (12 MW x 4 units and 20 MW x 5 units) are removed one by one from the assessment.

Figure 4 shows the EENS of PLS when the peaking units are removed one by one from the total generating system capacity. This figure implies that PLS can function as peaking units when the total generating capacity is within 3385-3305 MW. Meanwhile, Table 4 shows that CLS is a better alternative than PLS and peaking units. In certain times, the risk of adequacy deficit is significant, whereas in others, it is minimal or nonexistent. In general, peak periods have a higher risk rate than off-peak periods. For example, the winter season has a higher risk than other seasons.

Table 3. Impacts of PLS and CLS as alternatives to peaking units

\begin{tabular}{ccc}
\hline \multicolumn{3}{c}{ EENS (MWh /year) } \\
without load shifting & PLS & CLS \\
\hline 1471.0149 & 830.7562 & 73.2181 \\
\hline
\end{tabular}

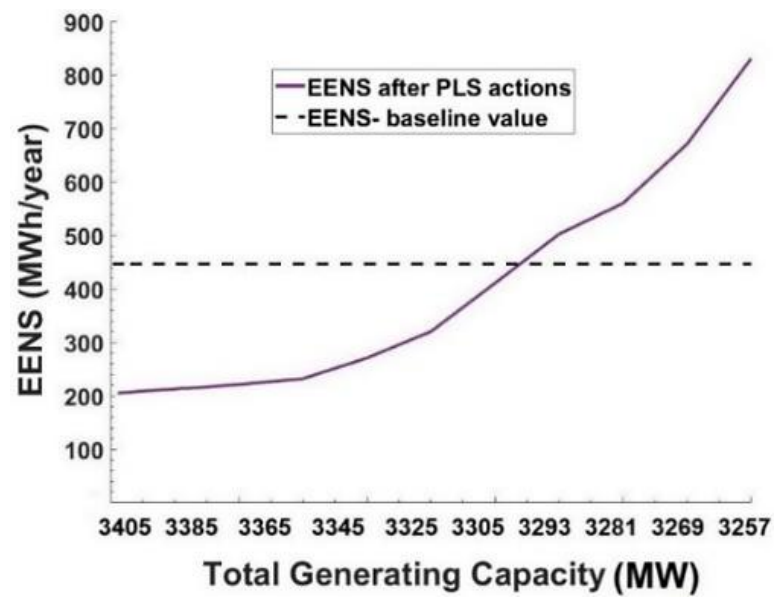

Figure 4. Impact of PLS on EENS as an alternative to peaking units 
Table 4. Impacts of PLS and CLS as alternatives to peaking units

\begin{tabular}{ccc}
\hline Total Generating Capacity (MW) & EENS (MWh/year)-PLS & EENS (MWh/year)-CLS \\
\hline 3405 & 212.1098 & 11.3456 \\
3385 & 221.1417 & 16.0026 \\
3365 & 231.9358 & 19.6258 \\
3345 & 270.6153 & 22.2345 \\
3325 & 320.1500 & 29.9821 \\
3305 & 410.5764 & 37.3491 \\
3293 & 502.4151 & 41.0345 \\
3281 & 560.1117 & 50.0029 \\
3269 & 670.9989 & 58.9316 \\
3257 & 830.7562 & 73.2181 \\
\hline
\end{tabular}

\section{DISCUSSION}

From the aforementioned results, the following points must be highlighted.

1) Peaking load units are typically needed for only a several hours per year, whereas base load units are needed nearly almost all of the time. Due to the variation of load levels during the periods when these units are needed, cycling units have a numerous start-up and shut-down operation every year. To ensure the optimal and effective functioning of a power plant, the more economical-effective units must be on duty more than the less economical-effective units. As a result, all generating units must be in optimal balance. Peaking load units are frequently required not just during peak hours, but also when total available capacity is insufficient to meet demand. Peaking load units are less contributing than base load units to provide energy and have a higher manufacturing cost. Furthermore, they are frequently employed during periods of high demand. As a result, the load shifting programme intends to reduce the average cost of production by avoiding the utilization of peaking load units. The load shifting programme, in other words, can operate as peaking load units.

2) The power system must have enough generation units to meet unpredictable demand and respond to outages and scheduled maintenance requirements. Consequently, load shifting may contribute substantially to a balanced load and generation side system performance. A load shifting method can be deployed to the power system as an alternative to building new generation capacity.

3) Both CLS and PLS programmes are designed to eliminate the utilization of peaking load units, improving reliability and lowering average generating costs. PLS can function as peaking units when the total generating capacity is within 3385-3305 MW. Meanwhile, CLS can be a better alternative than PLS and peaking units.

4) For power system planners, the distributions of predicted energy supplied and energy not supplied to each generating unit for IEEE-RTS owing to scheduled and unforeseen outages offer a useful metric. If an adequate load shifting strategy is established, all generating units will be in balance.

5) The load shifting programme exerts a considerable impact on EENS. However, if peak clipping surpasses 16 percent of peak demand, load shifting may deteriorate EENS. The inability to recover all of the cut energy during the off-peak time is responsible for this decline. If an effective and acceptable peak clipping rate is used, load shifting action gives a practical opportunity.

6) The risk of adequacy insufficiency is significant in some cases, whereas in another, it is minimal or nonexistent. Peak periods, in general, have a high danger rate. Off-peak hours, on the other hand, have a low danger rate. This finding implies that risk may be moved from an elevated-risk hour to a reducedrisk hour to some extent. As a result, by establishing an adequate load shifting method, risk balancing of daily hours can be accomplished.

The most significant advantage of incorporating CLS into sufficiency planning is the significant decrease in system reliability indices. That is, the findings of this study contribute to the management decision-making process. The following issues will be addressed in the future:

- Peaking and cycling load units' start-up and shutdown operations: The most crucial step in the operation of a generating unit is the start-up. Generation units need a particular loading time and a specified off time when they initially start up. Peaking and cycling load units have a large number of start-up and shutdown activities, which has a detrimental impact on total system performance. PLS implementation can help to mitigate this issue to some extent. During a time of frequent start-up and shutdown activities of cycling units, load shifting can be applied. Risk and manufacturing costs are reduced as a result of this adoption.

- Production cost: Electrical power system reliability may be improved during the planning phase by boosting supply adequacy, which raises starting costs. The associated expense may not worth the improved reliability. To make an appropriate planning choice of reliability level, a balance between investment cost and load shifting may be accomplished. 


\section{CONCLUSION}

This study investigates the overall framework for integrating a load-shifting technique with corrective and preventive actions as alternatives to peaking units. Corrective and preventive load management techniques aim to avoid the use of peaking units; hence, these techniques can be implemented instead of peaking units. The results show that preventive load management technique can function as peaking units when the total generating capacity is within specific limits. Meanwhile, corrective load management technique can be a better alternative than preventive load management and peaking units. The results of this study provide indicators for electric power utilities engaged in the planning phase of electrical power.

\section{ACKNOWLEDGEMENTS}

The authors would like to gratefully acknowledge Aliraqia University for supporting the research.

\section{REFERENCES}

[1] R. Billinton and W. Li, Reliability Assessment of electric power systems using Monte Carlo methods. Boston, MA: Springer US, 1994.

[2] C. W. Gellings, "Evolving practice of demand-side management," Journal of Modern Power Systems and Clean Energy, vol. 5, no. 1, pp. 1-9, Jan. 2017, doi: 10.1007/s40565-016-0252-1.

[3] W. C. Khoo, J. Teh, and C.-M. Lai, "Integration of wind and demand response for optimum generation reliability, cost and carbon emission," IEEE Access, vol. 8, pp. 183606-183618, 2020, doi: 10.1109/ACCESS.2020.3029273.

[4] J. Teh, "Adequacy assessment of wind integrated generating systems incorporating demand response and battery energy storage system," Energies, vol. 11, no. 10, p. 2649, Oct. 2018, doi: 10.3390/en11102649.

[5] W. C. Khoo, J. Teh, and C.-M. Lai, "Demand response and dynamic line ratings for optimum power network reliability and ageing," IEEE Access, vol. 8, pp. 175319-175328, 2020, doi: 10.1109/ACCESS.2020.3026049.

[6] J. Teh, C. Ooi, Y.-H. Cheng, M. Atiqi Mohd Zainuri, and C.-M. Lai, "Composite reliability evaluation of load demand side management and dynamic thermal rating systems," Energies, vol. 11, no. 2, p. 466, Feb. 2018, doi: 10.3390/en11020466.

[7] H. Jabir, J. Teh, D. Ishak, and H. Abunima, "Impacts of demand-side management on electrical power systems: A review," Energies, vol. 11, no. 5, p. 1050, Apr. 2018, doi: 10.3390/en11051050.

[8] H. J. Jabir, J. Teh, D. Ishak, and H. Abunima, "Impact of demand-side management on the reliability of generation systems," Energies, vol. 11, no. 8, p. 2155, Aug. 2018, doi: 10.3390/en11082155.

[9] R. Diewvilai, R. Nidhiritdhikrai, and B. Eua-arporn, "Demand side management worth evaluation under generation system planning framework," in 2012 9th International Conference on Electrical Engineering/Electronics, Computer, Telecommunications and Information Technology, May 2012, pp. 1-4, doi: 10.1109/ECTICon.2012.6254297.

[10] H. Salehfar and A. D. Patton, "Modeling and evaluation of the system reliability effects of direct load control," IEEE Transactions on Power Systems, vol. 4, no. 3, pp. 1024-1030, 1989, doi: 10.1109/59.32594.

[11] B. Zhou, S. Lu, W. Zhang, X. Wang, and T. Qian, "Analysis model for peak load regulation capacity of power system with multienergy resources involved in system regulation," in 2017 IEEE Conference on Energy Internet and Energy System Integration (EI2), Nov. 2017, pp. 1-6, doi: 10.1109/EI2.2017.8245478.

[12] F. Fattori and N. Anglani, "An instrumental contribution to include the impact of PV on capacity adequacy in long-term energy models," in 2017 IEEE International Conference on Environment and Electrical Engineering and 2017 IEEE Industrial and Commercial Power Systems Europe (EEEIC / I\&CPS Europe), Jun. 2017, pp. 1-6, doi: 10.1109/EEEIC.2017.7977590.

[13] J. Prasad, T. Jain, N. Sinha, and S. Rai, "Load shifting based DSM strategy for peak demand reduction in a microgrid," in 2020 International Conference on Emerging Frontiers in Electrical and Electronic Technologies (ICEFEET), Jul. 2020, pp. 1-6, doi: 10.1109/ICEFEET49149.2020.9186983.

[14] G. Liu and P. Mancarella, “Adequacy assessment of renewables-dominated power systems with large-scale energy storage," in 2019 29th Australasian Universities Power Engineering Conference (AUPEC), Nov. 2019, pp. 1-6, doi: 10.1109/AUPEC48547.2019.211877.

[15] L. Lu, P. Preckel, and D. Gotham, "Assessment of the reliability of Indiana's electricity generation system," in 41st North American Power Symposium, Oct. 2009, pp. 1-6, doi: 10.1109/NAPS.2009.5484037.

[16] S. A. Rashidaee and T. Amraee, "Generation expansion planning considering the uncertainty of yearly peak loads," in 2018 IEEE International Conference on Environment and Electrical Engineering and 2018 IEEE Industrial and Commercial Power Systems Europe (EEEIC / I\&CPS Europe), Jun. 2018, pp. 1-4, doi: 10.1109/EEEIC.2018.8493688.

[17] J. Oteng-Adjei, A.-M. I. Malori, and E. K. Anto, "Generation system adequacy assessment using analytical technique," in 2020 IEEE PES/IAS PowerAfrica, Aug. 2020, pp. 1-5, doi: 10.1109/PowerAfrica49420.2020.9219789.

[18] R. Billinton and D. Huang, "Sensitivity of system operating considerations in generating capacity adequacy evaluation," International Journal of Electrical Power \& Energy Systems, vol. 32, no. 3, pp. 178-186, Mar. 2010, doi: 10.1016/j.ijepes.2009.07.002.

[19] M. K. Metwaly and J. Teh, "Probabilistic peak demand matching by battery energy storage alongside dynamic thermal ratings and demand response for enhanced network reliability," IEEE Access, vol. 8, pp. 181547-181559, 2020, doi: 10.1109/ACCESS.2020.3024846.

[20] A. Sinha and M. De, "Load shifting technique for reduction of peak generation capacity requirement in smart grid," in 2016 IEEE 1st International Conference on Power Electronics, Intelligent Control and Energy Systems (ICPEICES), Jul. 2016, pp. 1-5, doi: 10.1109/ICPEICES.2016.7853528.

[21] S. Ncwane and T. Ngcobo, "Scenario-based analysis of the adequacy of a South African grid to supply peak demand in 2030," in 2021 Southern African Universities Power Engineering Conference/Robotics and Mechatronics/Pattern Recognition Association of South Africa (SAUPEC/RobMech/PRASA), Jan. 2021, pp. 1-6, doi: 10.1109/SAUPEC/RobMech/PRASA52254.2021.9377249.

[22] M. J. A. Husain Saleh, S. A. Abbas Hasan Abdulla, A. M. A. Aziz Altaweel, and I. S. Qamber, "LOLP and LOLE calculation for smart cities power plants," in 2019 International Conference on Innovation and Intelligence for Informatics, Computing, and Technologies (3ICT), Sep. 2019, pp. 1-6, doi: 10.1109/3ICT.2019.8910296. 
[23] R. N. Allan, R. Billinton, and N. M. K. Abdel-Gawad, "The IEEE reliability test system - Extensions to and Evaluation of the Generating System," IEEE Transactions on Power Systems, vol. 1, no. 4, pp. 1-7, 1986, doi: 10.1109/TPWRS.1986.4335006.

[24] P. Subcommittee, "IEEE reliability test system," IEEE Transactions on Power Apparatus and Systems, vol. PAS-98, no. 6, pp. 2047-2054, Nov. 1979, doi: 10.1109/TPAS.1979.319398.

[25] R. Billinton and D. Lakhanpal, "Impacts of demand-side management on reliability cost/reliability worth analysis," IEE Proceedings - Generation, Transmission and Distribution, vol. 143, no. 3, p. 225, 1996, doi: 10.1049/ip-gtd:19960190.

\section{BIOGRAPHIES OF AUTHORS}
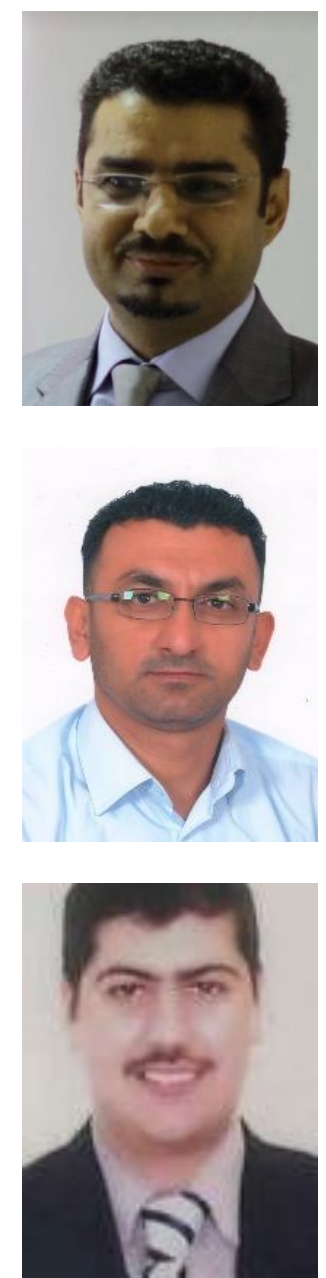

Asst. Prof. Dr. Malik Abdulrazzaq Jabbar Alsaedi (D) 8d SC P received B.Sc. degree in electrical engineering from university of technology and $\mathrm{M}$. Tech degree of engineering from JNTU, india and Ph.D. degree in control engineering from UTM, Malaysia. He had worked in industry on data acquisition systems and radar signal processing and analysis for over three years. He was a lecturer at University of mysan for four years. Currently, he works as head of Electrical Engineering department at Al-Iraqia University. His research interests focus on contemporary development of electrical abd communication applications. He can be contacted at email: maliksaady@yahoo.com.

Dr. Hussein Jumma Jabir (iD 81 SC P was born in Tal Muhammad, Baghdad, Iraq, in 1977. He received the B.Sc. degree in electrical engineering from the University of Technology, Baghdad, Iraq, in 2003, and the M.Tech. degree in electrical power engineering from Jawaharlal Nehru Technological University, Hyderabad, India, in 2014 and the Ph.D. degree in electrical power systems engineering with the Universiti Sains Malaysia, Nibong Tebal, Malaysia. He is currently a lecturer with the Department of electrical engineering in Aliraqia university, Baghdad, Iraq. He has authored or coauthored more than 6 publications, with $4 \mathrm{H}$ index and more than 161 citations. His research interests include electrical power systems reliability and load shaping. He can be contacted at email: hjjahmn@gmail.com.

Asst. Prof. Dr. Baraa Munqith Albaker (iD 81 SC P received both B.Sc. degree in electrical engineering and M.Sc. degree in computer and control engineering from University of Baghdad, Iraq, and Ph.D. degree in control engineering from University of Malaya, Malaysia. $\mathrm{He}$ had worked in industry on data acquisition systems and radar signal processing and analysis for over three years. He was a lecturer at University of Baghdad for four years. Next, he was a senior lecturer of UMPEDAC research Centre, University of Malaya for two years. Currently, he works as head of Networks Engineering department at Al-Iraqia University. His research interests focus on contemporary development in computer and control applications. He can be contacted at email: baraamalbaker@ymail.com. 